\title{
The role of digital marketing in improving the efficiency of the product distribution system of agricultural enterprises in the Krasnoyarsk Region
}

\author{
Olga Nezamova ${ }^{1, *}$, and Julia Olentsova ${ }^{1}$ \\ ${ }^{1}$ Krasnoyarsk State Agrarian University, Krasnoyarsk, Russia
}

\begin{abstract}
The article considers the system of product distribution and the possibilities of its development and improvement through the use of progressive, digital marketing technologies on the example of agricultural enterprises in the Krasnoyarsk Region in Russia. This problem becomes particularly relevant in times of crisis, when the need to reduce the cost of production increases. The process of product distribution is quite expensive, it has a number of organizational disadvantages. This process does not fully use modern digital marketing technologies to form a customer base, which would significantly speed up the process of product distribution. The article identifies the factors that restrain the development of the process of product distribution, which include: long distances between the subjects of the process, insufficient development of the transport network, its slow renewal, lack of distribution centers and their weak technical equipment, insufficiently developed infrastructure. Also, for a more effective organization of product distribution channels, it is necessary to actively implement modern digital marketing technologies in the process of product distribution, which will help to form a customer base and develop long-term communications with potential customers.
\end{abstract}

\section{Introduction}

The importance of the agricultural sector in the country's economy is difficult to overestimate and, therefore, its effectiveness has always been of paramount importance. The efficiency of the agricultural sector is possible only with the optimal functioning of all its constituent elements. In this regard, the process of product distribution for agricultural products deserves special attention, since it is in this process that many Russian scientists note significant, unjustified losses and reserves for improving the efficiency of the agro-industrial complex. The Krasnoyarsk region in Russia has an agricultural and industrial specialization, its own infrastructure complex and a regional organization of the agro-industrial complex. The system of product distribution in the agro-food market largely determines the efficiency of the agro-industrial complex as a whole. In addition, the process of product distribution in the region is organized mainly according to traditional marketing principles and does not use the capabilities of modern digital technologies to attract new customers, form a customer base and improve marketing communications in order to prepare the market for the moment of receiving goods.

The purpose of this study is to analyse the organization of the product process distribution in the agro-industrial complex, which has developed for this period in the food market of the Krasnoyarsk region, to identify the factors that most significantly affect its optimization, to offer tools for adapting to modern market conditions using advanced digital marketing technologies. This will reduce the cost of a useless audience, increase the customer base and increase sales efficiency.

To conduct this study, we used data from the reports of the Ministry of Agriculture, materials of scientific conferences, Internet resources, etc.

The novelty of this offer is in the fact that through the use of digital marketing, we provide a comprehensive, personalized, innovative approach to the formation of communications with the consumer and prepare the market in advance for the reception of goods.

Communication with the consumer is carried out continuously throughout the period from his acquaintance with the product to making a purchase. We have proposed measures to improve the process of product distribution and the introduction of innovative marketing tools (sales funnels) for market preparation.

This problem, due to its relevance, practical significance and lack of elaboration, was given a lot of attention by Russian scientists, such as N. D. Avarsky, E. V. Anisimov, E. V. Vasiliev, M. M. Ishmuratov, S. V. Koteev, K. V. Kulagin, V. V. Lavrikov, S. U. Nuraliev, A. N. Osipov, N. A. Prolygina. The problems of development, improvement and functioning of the agrifood market are revealed in the works of such scientists as A. I. Altukhov, N. A. Borkhunov, A. P. Zinchenko, G.

\footnotetext{
* Corresponding author: tutor.eng@yandex.ru
} 
A. Polunin, A. E. Romanov, A. F. Serkov, Silaeva and a number of other scientists.

\section{Materials and methods}

As a methodological basis for the study, the works of foreign scientists on the problems of improving the system of product distribution in the agro-industrial complex were also used.

Methods of statistical, economic and logical analysis, methods of economic comparison were used in the work on the article. The analytical materials of individual agricultural enterprises, scientific works of research institutions and materials of scientific conferences and seminars served as the information base of the study.

The improved issues for the process of product distribution are global in nature and were considered within the region. And the issue of introducing innovative marketing technologies, in particular, the formation of a sales funnel, was considered on the example of LLC "Iskra". This company is located in the Krasnoyarsk region and is engaged in agricultural activities, producing a wide range of products. One of the main activities is the production of high-quality dairy products. Since the market of dairy products is highly competitive, and in times of crisis, sales of products are difficult, it was decided to more actively implement digital marketing technologies in order to improve sales of products, establish long-term communication links with wholesalers and expand the customer base.

\section{Results and discussions}

The agro-food market is a complex system connected by the market mechanism of functioning and consisting of product markets and the corresponding infrastructure, which implies the presence of wholesale and retail trade enterprises, advertising and consulting agencies, various organizations that provide information services [1-4].

In the modern market economy, no product market is able to do without a developed and efficient system of product distribution. This is even more relevant for the agro-food market, since this market deals with perishable products, the need to store them in special conditions, requires a high speed of turnover and the presence of transport and distribution centers. The process of product distribution has a significant impact on the formation of the final product price. In developed countries the cost of product distribution accounts for $25-35 \%$ of total costs. According to some enterprises of the Krasnoyarsk region, this figure reaches $50 \%$. Therefore, rationalizing these costs will reduce the final price of food products and make them more affordable for the consumer. The formation of effective product distribution systems also helps to increase the level of service, reduce transport costs, and minimize inventory. In addition, the process acceleration of product distribution increases the turnover of agricultural products, which helps to keep the quality of agricultural products higher.

Despite the conducted research, there are a number of unresolved problems in the issues of product distribution for agricultural products. The process of product distribution requires further development and improvement [5-8].

For example, it is necessary to consider and optimize the management of product distribution, from the point of view of the enterprises integration that produce, process, transport and trade products. The issues of the most complete utilization for the production capacities of processing enterprises, ensuring uninterrupted trade, and creating optimal reserves also deserve attention. It is also necessary to pay more attention to the issues of state regulation for the product distribution and to propose the main directions of this regulation in order to ensure its focus on social needs and orientation to the existing market mechanisms.

The process of product distribution for agricultural products is even more complex than the product distribution of industrial products due to certain features. For example, agricultural products have large physical volumes, the production of these products depends on climatic conditions, the production cycle is quite long, the products have a pronounced seasonality, which entails uneven sales, sharp seasonal price fluctuations, short storage life of products.

Significant problems in the organization of product distribution are associated with an insufficient level of customer service. To a large extent, this problem could be solved by the organization of a large number of technically equipped distribution centers, which would have a positive impact on the efficiency of the agroindustrial complex as a whole [9-12].

After studying the situation on the food market of the Krasnoyarsk region, we see that the demand is largely determines a number of economic factors such as income level, the level of prices for agricultural products, the supply structure of agricultural products.

It is necessary to analyse many issues that are closely related to this process to develop measures for improving the product distribution. This includes the development of optimal product distribution schemes, the development of the processing industry, the processing improvement of food raw materials, the choice of the most efficient method of transportation for each type of product, the reduction and possibility of cost reducing for storage and transportation of products, and the prospects for the development of market infrastructure.

In the Krasnoyarsk region, the following things can be noted as the reasons that restrain the process of improving the product distribution:

- the scale of the territory and the large distances between the subjects of the process;

- insufficient development of the transport network;

- incomplete provision of vehicles;

- slow vehicle upgrades;

- insufficient number of distribution centers;

- low technical equipment of distribution centers;

- insufficiently developed infrastructure (transport, logistics, market):

- imbalance of import and export cargo flows;

- insufficiently active marketing activities in the process of product distribution; 
- insufficient legislative framework for regulating the process of product distribution.

As already mentioned, the process of developing the product distribution system requires the presence of a developed infrastructure in the region. At present, the development of the product distribution system in the Krasnoyarsk region could be greatly facilitated by an increase in the number of enterprises or small workshops for processing agricultural products. These infrastructure facilities are clearly not enough at the moment. It should be noted that in addition to improving the process of product distribution (reduction of transportation, increase in the storage life of products) this will help to increase the employment of the local population and increase the level of income [13-17].

Based on the experience study of Russain western regions, in our opinion, it is advisable to develop the system of product distribution in several areas together, which will help to get better results. This approach is currently recommended by the state in the framework of the territorial development program. This approach is characterized by the creation of specialized clusters, the unifying principle of which is the creation of a common product and the use of joint technologies.

Such clusters, as a rule, are built on the basis of cooperation (intersectoral and territorial) and are a selfregulating organization. Funding should be provided on the basis of public support and private investment. Clusters organize their work according to the rules developed by the cluster members. This cluster should involve such participants as peasant (farmer) farms and personal subsidiary farms, so small forms of management. Within the cluster, it is easier to optimize transportation services, calculate and optimize the capacity utilization of processing enterprises in a certain zone.

In addition, in our opinion, not enough attention is paid to the use of advanced digital marketing tools in the process of product distribution to form the market for goods, form a customer base, first familiarize potential buyers with the product, provide customers with information about the product, the place and conditions of purchase, and a number of other issues [18-22].

Digital marketing contributes to the effective promotion of products and businesses through digital channels, which significantly increases the targeting of marketing activities, expands the reach of consumers and at the same time saves the budget and helps to adapt advertising to a specific consumer. This area of marketing is often referred to as digital marketing.

The most common channels of digital promotion are considered to be search engines, websites, social networks, e-mail, and various mobile offers. Such digital promotion channels as digital television, game consoles, interactive screens are currently not very actively used, but are in constant development. In the United States and a number of other developed countries in Europe, digital advertising costs exceed TV advertising costs, since 2017 , in some industries, up to $40 \%$ of the advertising budget is spent on digital advertising. In Russia, this figure is much lower and not all enterprises actively use digital marketing technologies, but their development is increasing [23-25].

The main factors that contribute to the development of digital technologies are:

- availability of large data sets and the ability to process them quickly;

- the ability to build long-term relationships with customers, which can be built on a large number of channels;

- the ability to quickly receive feedback from the consumer and adjust advertising activities.

It is advisable to create an effective sales system, without losses, by building a sales funnel. It makes it possible to understand what the client wants and build a benevolent and long-term relationship with him. The sales funnel represents the customer's path from the first click to making a purchase, it is a sequence of stages that the customer goes through before making a purchase. Digital marketing helps to go this way as comfortably as possible.

LLC "Iskra" is currently working on creating a sales funnel using digital marketing to improve the effectiveness of promoting its products. The classic model includes 4 steps or stages that correspond to the consumer's thinking. They are usually referred to by the abbreviation AIDA, which reveals the sequence of the client's thinking: Attention, Interest, Desire, Action.

The second stage assumes that the customer is interested in the product and needs to help them compare their products with similar ones, make them think about buying, but not offer it too aggressively, which can scare the customer away. At this stage, the customer needs to offer additional information about their product in an interesting way.

At the third stage, it is necessary to encourage the customer to make a purchase. It is proposed to develop methodological recommendations for the employee in charge of digital marketing activities, with a selection of very interesting content that does not sell, but helps to choose a product, data from product quality studies, inform the consumer about discounts, bonuses, preferential delivery, and various guarantees. It is necessary to understand that it is during this period that the consumer compares various product options and bonuses with the products and bonuses of competitors, so the product must be presented in the most favourable light and speed up the decision to purchase. These offers should be very tempting and time-limited, and should encourage quick decision-making.

The fourth stage involves the customer's action to make a purchase. Thus, the client reaches the bottom of the funnel, but this does not mean that the work with him is finished. It should be remembered that a lot of work has been done with the client and it will be much easier to persuade him to re-purchase than initially because he already trusts the company to some extent, knows about the company and is ready to cooperate. You need to continue working with this client, push him to further purchases and make efforts to retain the client [26-29].

Thus, we see that the sales funnel is a fairly effective means of improving the promotion of products and helps to form the market in the process of product distribution. 
At the company LLC "Iskra", it was revealed that due to the sales funnel there is an opportunity to determine where our customers (consumers of products) are from, which tools of influence are more preferable for them, to track where and by what we lose customers, how this can be prevented, to predict the possibility of increasing profits and market coverage.

Despite the fact that the work on the application of digital marketing is still at the very beginning, however, it has already affected the expansion of the customer base and an increase in market share. The company also signed a number of contracts for the supply of meat, dairy, vegetable products and semi-finished products. Currently, work is underway to conclude contracts for the supply of products to cafes and restaurants. It is planned to expand trade from mobile counters, as this form of trade is well suited for perishable products.

\section{Conclusion}

New media, in comparison with traditional ones, have a number of advantages that are in demand by modern consumers. For example, they transmit content in a more diverse way. Such messages can use text, numbers, graphs, photos, videos, pictures, and other communication elements. However, the use of new media requires that employees have certain professional skills and have sophisticated technical equipment.

The new media can run $24 / 7 / 365$, which is not available to employees, and is personalized because it focuses on customer feedback. Access to the information is round-the-clock, and the information is updated periodically. A significant advantage of digital marketing is a wider audience reach.

The number of people using various gadgets to get information, including advertising, is constantly increasing. Only $28 \%$ of respondents use the Internet, compared to $24 \%$ in 2020 , these are usually young people. But in combination with other means of communication, the Internet is used by about $70 \%$ of respondents, compared to $67 \%$ in 2020 . In in-depth interviews, people note that they have more confidence in the information received from the Internet than in the information received from television channels. In our opinion, it is the Internet information that is most appropriate to use for the formation of relations between the subjects of the food market. Today, an increasing number of customers prefer digital marketing.

In today's fast-developed world, all processes (economic, technological, social) are developing very dynamically and require constant improvement and adaptation to changing market conditions. This fully applies to the process of product distribution. The article analyses the main directions of improving the process of product distribution of the agro-food market in the Krasnoyarsk region. The system of product distribution in the agro-food market largely determines the efficiency of the agro-industrial complex as a whole.

The organization of product distribution in the Krasnoyarsk region is based mainly on traditional approaches. Product distribution is one of the functions of the agro-industrial complex, which contains significant reserves for improving the efficiency of the agro-industrial complex as a whole. The modern world is characterized by a very rapid change in technologies, the organization of production processes, the system of methods and means of communication, the creation of new organizational forms of management, changing approaches to stimulating purchases, more promising digital technologies are being introduced. However, all these achievements are not widely implemented in the process of product distribution, which affects its efficiency and prevents the use of existing reserves to reduce costs and increase the speed of the processing product distribution.

In the process of working on the article, a number of problems were identified that require immediate solution at the present time. The main problems that restrain the further development of the product distribution process are: insufficient infrastructure development, a small number of distribution centers and their insufficient technical equipment, the development of a product distribution system based on clusters.

Especially acute at this stage is the issue of improving sales promotion and using the capabilities of modern digital technologies to attract new customers, build a customer base and improve marketing communications in order to prepare the market for the moment of goods receipt.

In our opinion, it is advisable to introduce sales funnels in the product distribution channels, which will raise the communication in the product distribution channels to a qualitatively new level and make them highly effective and long-term and will be focused on the target consumer. When the goods arrive on the prepared market, we will get a significant acceleration of the process of product distribution.

\section{References}

1. N.A. Dalisova, M.V. Karaseva, State support for export of agro-industrial complex products of the Krasnoyarsk region, IOP Conference Series: Earth and Environmental Science, 548 (2), 022093 (2020)

2. A.V. Rozhkova, N.A. Dalisova, E.V. Stepanova, M.V. Karaseva, Export potential development of wild plants, IOP Conference Series: Earth and Environmental Science, 421 (8), 082020 (2020)

3. S.A. Kapsargina, N.M. Chebokchinova, Agricultural development for improving the wellbeing of the rural population of the Republic of Khakassia, IOP Conf. Ser.: Earth Environ. Sci., 548, 022049

4. A.S. Mikhalev, V.S. Tynchenko, V.V. Kukartsev, V.A. Kukartsev, A.V. Rozhkova, Storage and analysis of natural resources information in various territories, Journal of Physics: Conference Series, 1661 (1), 012181 (2020)

5. O.V. Zinina, N.A. Dalisova, N.I. Pyzhikova, J.A. Olentsova, Development prospects of the Krasnoyarsk region agroindustrial complex in the 
export conditions, IOP Conference Series: Earth and Environmental Science, 315 (2), 022068 (2019)

6. P. Chepurnoy, Identification and falsification of food products: a textbook (Moscow, Dashkov and $\left.\mathrm{K}^{\mathrm{o}}, 2002,460\right)$

7. O.A. Nezamova, J.A. Olentsova, Monitoring Consumer Behaviour in the Food Market in the Krasnoyarsk Region of Russia, International Conference on Efficient Production and Processing (ICEPP-2020), 161, 01080 (2020)

8. E. Stepanova, A. Rozhkova, Resource Saving Technologies for Rapeseed Cultivation at the Regions of the Russian Federation, E3S Web of Conferences, 161, 01075 (2020)

9. Z. Biktimirova, Quality of life: food security, Economist, 2, 78-85 (2004)

10. N.A. Dalisova, A.V. Sharopatova, M.V. Karaseva, Value and role of the strategic management in the development of agricultural enterprises, IOP Conference Series: Earth and Environmental Science, 548 (2), 022102 (2020)

11. A. Rozhkova, J. Olentsova, Development of New Technological Solutions for the Dairy Industry, E3S Web of Conferences, 161, 01086 (2020)

12. A.O. Stupin, V.V. Kukartsev, V.S. Tynchenko, A.I. Cherepanov, A.V. Rozhkova, Management modelling of the natural resources extraction station by agency modelling means, Journal of Physics: Conference Series, 1661 (1), 012196 (2020)

13. Y. Koloskova, N. Dalisova, Z. Shaporova, The role of human capital in the development of agribusiness, IOP Conference Series: Earth and Environmental Science, 315 (2), 022103 (2019)

14. D.S. Shalaeva, O.I. Kukartseva, V.S. Tynchenko, S.V. Aponasenko, E.V. Stepanova, Analysis of the development of global energy production and consumption by fuel type in various regions of the world, IOP Conference Series: Materials Science and Engineering, 952 (1), 012025 (2020)

15. D.V. Eremeev, A.A. Boyko, A.V. Kukartsev, E.V. Mylnikova, L.N. Korpacheva, The use of mathematical calculations to determine the feasibility of borrowing in the planning period, Journal of Physics: Conference Series, 1582 (1), 012027 (2020)

16. D. Goncharov, Marketing of food products in Russia (Moscow, Finance and Statistics, 2013, 176)

17. O.V. Zinina, O.I. Antamoshkina, J.A. Olentsova, Analysis of innovative activity in the agroindustrial complex of the Krasnoyarsk region, IOP Conference Series: Earth and Environmental Science, 548 (2), 022033 (2020)

18. A.A. Boyko, V.V. Kukartsev, V.S. Tynchenko, A.V. Rozhkova, S.V. Aponasenko, Using linear regression with the least squares method to determine the parameters of the Solow model, Journal of Physics: Conference Series, 1582 (1), 012016 (2020)
19. N.V. Fedorova, N.N. Dzhioeva, V.V. Kukartsev, A.R. Ogol, V.S. Tynchenko, et. all, Methods of assessing the efficiency of the foundry industrial marketing, IOP Conference Series: Materials Science and Engineering, 734 (1), 012083 (2020)

20. A.A. Belousov, E.N. Belousova, E.V. Stepanova, The influence of soil protection technologies on the content of organic substance in leached chernozem, IOP Conference Series: Earth and Environmental Science, 421 (3), 032001 (2020)

21. O. Antamoshkina, O. Zinina, J. Olentsova, The formation of the alternative list in the output of competitive ecological products, International Multidisciplinary Scientific GeoConference Surveying Geology and Mining Ecology Management, SGEM, 18 (5.3), 863-870 (2018)

22. O.V. Zinina, N.A. Dalisova, J.A. Olentsova, Dynamics and structure of manufacturing bread and bakery products in the Krasnoyarsk region, IOP Conference Series: Earth and Environmental Science, 548 (2), 022028 (2020)

23. P. Hazell, C. Poulton, S. Wiggins, A. Dorward, The Future of Small Farms: Trajectories and Policy Priorities, World Development, 38 (10), 1349-1361 (2010) DOI: 10.1016/j.worlddev.2009.06.012

24. E.N. Kiseleva, O.V. Vlasova, E.B. Konnova, Market of food products (Moscow, University textbook, 2015, 144)

25. Kaishev, S. Seregin, Food industry in 2003: Results, perspective, Economist, 6, 74-56 (2004)

26. E.V. Stepanova, Strategic directions for the development of agricultural exports in the regions of the Russian Federation, IOP Conference Series: Earth and Environmental Science, 548 (2), 022098 (2020)

27. A.V. Rozhkova, J.A. Olentsova, Development of New Technological Solutions for the Dairy Industry International Conference on Efficient Production and Processing (ICEPP-2020), 161, 01086 (2020)

28. N.A. Dalisova, I.I. Grishina, Personnel training as a factor in the formation of the export potential of the agro-industrial complex of the region, IOP Conference Series: Earth and Environmental Science, 315 (2), 022072 (2019)

29. O.A. Nezamova, J.A. Olentsova, Adaptation problems of the food market to modern conditions, IOP Conference Series: Earth and Environmental Science, 548 (8), 082023 (2020). 